\title{
Gödel: The Third Degree
}

\author{
Graham Oppy
}

$\mathrm{K}$

URT GÖDEL WAS one of the greatest logicians of all time. His major results include the completeness of the first-order predicate calculus, ${ }^{1}$ his famous incompleteness theorems, ${ }^{2}$ and his proof that the Axiom of Choice and the Continuum Hypothesis are consistent with Zermelo-Frankel set theory. ${ }^{3}$ Gödel also found solutions to the equations of general relativity in which there are closed time-like curves, and suggested that this is good reason to suppose that time is not real. ${ }^{4}$

Gödel was interested in philosophy; in particular, he was a great admirer of Gottfried Leibniz. His interest in ontological arguments sprang from reflection upon Leibniz's attempts to improve René Descartes ontological arguments. In the eleventh century, in his Proslogion, St. Anselm gave a derivation of the existence of that than which no greater can be conceived. ${ }^{5}$ In the seventeenth century, Descartes gave various derivations of the existence of a being that possesses all perfections. ${ }^{6}$ Leibniz refined Descartes' argument by providing a derivation of its implicit premise: that it is possible for something to have all perfections.?

In the early 1940s, Gödel produced the first of several derivations that aimed to formalize Leibniz's development of Cartesian ontological arguments. There is no evidence that Gödel showed his derivations to anyone until the early 1970s, when, under the mistaken belief that he was on his deathbed, he showed some of the relevant notebooks to Dana Scott. With Gödel's permission, Scott copied out one of the derivations, which began to circulate privately.

Howard Sobel finally published Scott's derivation in 1987 , along with a different derivation that had been found in one of Gödel's notebooks. Sobel's main contribution to the subsequent discussion was his claim that Gödel's axioms entail a modal collapse in which all truths are necessarily true. It seemed obvious to him, Sobel observed, that some of Gödel's axioms are false.

In 1990, C. Anthony Anderson claimed that the modal collapse identified by Sobel can be averted by a relatively minor adjustment to Gödel's axioms. ${ }^{8}$

While questions about modal collapse have continued to attract interest, Anderson's paper was influential in call- ing attention to possible improvements or simplifications of Gödel's derivations. In recent years, Alexander Pruss has produced a series of papers in which he discusses a family of Gödel-like higher-order ontological arguments.

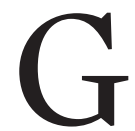

ÖDEL'S ONTOLOGICAL ARGUMENT is formulated in a third-order modal logic. The base of the logic is a classical first-order predicate calculus. To this, we add: (i) second-order predicates and quantification over first-order predicates; (ii) third-order predicates and quantification over second-order predicates; (iii) the standard modal operators; and (iv) a version of the modal logic S5. ${ }^{9}$

Definitions:

- D0: A entails a property $B={ }_{\text {df. }}$ necessarily, anything that has the property A has the property $\mathrm{B}$.

- D1: A is an essential property of $x=_{\mathrm{df}}$. necessarily, if $x$ exists, $x$ has the property A.

- D2: $x$ is God-like $=_{\text {df. }}$ all of $x$ 's essential properties are positive, and all positive properties are essential properties of $x$.

- D3: $\mathrm{EA}={ }_{\mathrm{df}}$ the property of having A essentially.

- D4: A is strongly positive ${ }_{\text {df. }}$ the property EA is positive.

- D5: $x$ is God $^{\dagger}$-like ${ }_{\text {df. }} x$ has all strongly positive properties.

- D6: A is uniqualizing $=_{\mathrm{df} .}$ it is impossible for there to be two different things that have the property A.

D2 makes use of the notion of a positive property. Although the notion is not defined, axioms invoked impose constraints upon its interpretation.

Axioms:

- $\mathrm{Al}$ : If $\mathrm{A}$ is positive, then $\sim \mathrm{A}$ is not positive.

- A2: If $\Delta$ is a set of positive properties, and $\Delta$ entails B, then $B$ is positive.

- A3: If A is positive, then necessarily A is positive.

- A4: Being God-like is a positive property.

- A5: Necessarily existing is a positive property.

- A6: Being God"-like is a positive property.

- A7: There is a strongly positive uniqualizing property. 
Lemmas:

- L1: A1, A2 $\vdash$ Any non-empty set of positive properties is possibly instantiated, i.e., it is possible for there to be something that has all of these properties.

- L2: A1, A2, A4 $\vdash$ If A is strongly positive, then there is a necessarily existing being that has A essentially.

- L3: A2, A3 $\vdash$ If God†-likeness is positive, then it is strongly positive.

\section{Theorems:}

- T1: A1, A2, A5 $\vdash$ There is a necessarily existing being.

- T2: A1, A2, A3, A4, A5 $\vdash$ There is a necessarily existing God-like being.

- T3: A1, A2, A5, A6 $\vdash$ There is a necessarily existing God†-like being.

- T4: A1, A2, A6, A7 $\vdash$ There is exactly one God†-like being.

The key to Gödel's ontological argument is understanding the proof of L1. Suppose that $\Delta$ is a non-empty set of positive properties; and that the properties in $\Delta$ are not possibly instantiated. Anything that has all of the properties in $\Delta$ has, by D0, the negation of at least one. By A1, the entailed property is not positive, since it is the negation of a property that is positive; but, by $\mathrm{A} 2$, the entailed property in $\Delta$ is positive, since it is entailed by a set of properties all of which are positive. This is a contradiction. The prope ties in $\Delta$ are possibly co-instantiated.

Given L1, it is a short step to T1. The property of necessarily existing is, by A5, a positive property. Hence, by L1, the property of necessarily existing is possibly instantiated.

T2 is very nearly the major result from Gödel's notebooks. This is because, in place of Al, Gödel had:

- $\mathrm{Al} 1^{*}: \mathrm{A}$ is positive if and only if $\sim \mathrm{A}$ is not positive.

$\mathrm{Al}^{*}$ leads to modal collapse. The problem arises because Gödel's third-order logic included an abstraction operator: for any sentence $\varphi$, there is the property $\lambda x \varphi$, i.e. the property of being such that $\varphi$.

- A8: For any proposition $\varphi$ and any object a, $[\lambda x \varphi] \mathrm{a}$ if and only if $\varphi$.

We then have the following theorem:

- T5: A1*, A8 $\vdash$ If there is a necessarily existing God-like being and $\varphi$ is true, then $\varphi$ is necessarily true.

From T2 and T5, we can immediately conclude that all truths are necessary.

While it might be possible to dispute whether Gödel would have accepted A8, most people who have consid- ered the matter have supposed that it was a mistake on Gödel's part to accept $\mathrm{Al}^{*}{ }^{10}$ Since $\mathrm{A1} *$ can be replaced by Al without loss in all of the relevant derivations, it seems that nothing of value is lost if we work with Al instead.

T3 and T4 are results due to Pruss that work with different assumptions from those that figure in Gödel's ontological argument. In a comprehensive discussion of higher-order ontological arguments, these results should be considered alongside Gödel's ontological arguments. Any such discussion would also involve the derivations provided by Maydole. ${ }^{11}$

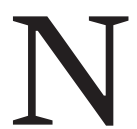

OT ALL PHILOSOPHERS have embraced third-order modal logic. In the middle of the twentieth century, W. V. O. Quine argued against both the higher-order predicate calculus and modal logics that admitted the distinction between essential and non-essential individual properties. ${ }^{12}$ Those persuaded by these arguments will not be enthusiastic in their assessment of higher-order ontological arguments. For those unmoved by Quine's objections, there remains the question whether Gödel's arguments are successful proofs of their conclusion. $^{13}$

Suppose there is a higher-order property $\mathbf{P}$ such that

1. For all first-order properties $\mathrm{P}$, if $\mathbf{P}(\mathrm{P})$ then $\sim \mathbf{P}(\sim \mathrm{P})$; and

2. For all non-empty sets of first-order properties $\Delta$, if, for all $\mathrm{P} \in \Delta \mathbf{P}(\mathrm{P})$, and $\Delta$ entails $\mathrm{Q}$, then $\mathbf{P}(\mathrm{Q})$.

L1 affirms for any non-empty set of first-order properties $\Delta$, that if for all $\mathrm{P} \in \Delta, \mathbf{P}(\mathrm{P})$, it is possible that for all $\mathrm{P} \in \Delta, \mathrm{P} x$. Contraposition immediately implies that there cannot be a higher-order property $\mathbf{P}$ such that

1. For all first-order properties $\mathrm{P}$, if $\mathbf{P}(\mathrm{P})$ then $\sim \mathbf{P}(\sim \mathrm{P})$; and

2. For all non-empty sets of first-order properties $\Delta$, if, for all $\mathrm{P} \in \Delta \mathbf{P}(\mathrm{P})$, and $\Delta$ entails $\mathrm{Q}$, then $\mathbf{P}(\mathrm{Q})$; and

3. For all $\mathrm{P} \in \Omega, \mathbf{P}(\mathrm{P})$.

Suppose that nothing exists necessarily. If there are no necessary beings then it is not possible that there are necessary beings. If it is impossible that there are necessary beings, then the property of existing necessarily entails every property; hence, in particular, it entails the property of not existing necessarily. If existing necessarily possesses some higher-order property, then, by (2), the property of not existing necessarily possesses that same higher-order property, and, by (1), the property of not existing necessarily fails to possess that same higher-order property. Contradiction! If nothing exists necessarily and the property of existing necessarily possesses some higher-order property, then it cannot be that both (1) and (2) are true of that higher-order-property.

Suppose, instead, that the only thing that necessarily exists is the initial singularity from which our universe 
emerges. Every possible world starts with that initial singularity, and diverges from the actual world only because chance plays out differently. There are no causes beyond natural causes; it is impossible for there to be gods. The initial singularity certainly has essential properties, whether or not they are known. The set of essential properties comprise the $\xi$-properties. It follows that:

1. For all first-order properties $\mathrm{P}$, if $\xi(\mathrm{P})$ then $\sim \xi(\sim \mathrm{P})$; and

2. For all non-empty sets of first-order properties $\Delta$, if, for all $\mathrm{P} \in \Delta \xi(\mathrm{P})$, and $\Delta$ entails $\mathrm{Q}$, then $\xi(\mathrm{Q})$; and

3. There is a set $\Omega$ such that, for all $\mathrm{P} \in \Omega \xi(\mathrm{P})$, and for all $\mathrm{P} \notin \Omega \sim \xi(\mathrm{P})$; and

4. $\xi$ (Necessarily Existing).

\section{Whence:}

- T5: (1), (2) (4) $\vdash$ There is a necessarily existing being.

- T6: (1), (2), (3), (4) $\vdash$ There is a necessarily existing initial singularity.

Unless there is an account of positive properties that provides some additional justification for (a) preferring the premises of Gödel's arguments to the premises of parallel arguments for a necessarily existing initial singularity, and (b) supposing that necessary existence is a positive property, Gödel's arguments are not successful proofs of their conclusion.

$\mathrm{P}$ RUSS SUGGESTS FIVE different accounts of what it is to be a positive property that might be utilized by a proponent of higher-order ontological arguments: ${ }^{14}$

a. $\mathrm{P}$ is positive ${ }_{1}{ }_{\text {df. }}$ it is better to have $\mathrm{P}$ than to lack $\mathrm{P}$;

b. $\mathrm{P}$ is positive ${ }_{2}{ }_{\mathrm{df}}$. having $\mathrm{P}$ in no way detracts from excellence but lacking $\mathrm{P}$ does detract from excellence;

c. $\mathrm{P}$ is positive ${ }_{3}={ }_{\mathrm{df} .} \sim \mathrm{P}$ is negative;

d. $\mathrm{P}$ is positive ${ }_{4}{ }_{\mathrm{df}}$. either $\mathrm{P}$ is a conjunction of simple, positive, absolute properties or else $\mathrm{P}$ is entailed by a conjunction of such properties; and

e. $\mathrm{P}$ is positive ${ }_{5}{ }_{\mathrm{df}}$, having $\mathrm{P}$ does not entail being limited but lacking $\mathrm{P}$ does entail being limited.

Some of these accounts are subject to particular and immediate difficulties.

Given (a), neither A1 and A2 seem plausible. For any $\mathrm{F}$ and $\mathrm{G}, \mathrm{F}$ entails $\mathrm{FV}$ G. If it is better to have $\mathrm{F}$ than not to have $\mathrm{F}$, and better not to have $\mathrm{G}$ than to have $\mathrm{G}$, then symmetry would suggest that $F \vee G$ is neither one nor the other. (d) is not a proper definition since 'positive' appears both in the definiens and in the definiendum. (c) violates the obvious requirement that a definition does not invoke terms that are as badly in need of definition as the term being defined. What is it to be a negative property? Who knows! Neither (f) nor (g) is of any help: f. $P$ is negative $=_{\text {df. }}$ it is worse to have $P$ than to lack P; and g. $\mathrm{P}$ is negative ${ }_{d f}$. $\mathrm{P}$ is a conjunction of simple, negative, absolute properties or $\mathrm{P}$ is entailed by a conjunction of such properties.

There is a more general difficulty: (a), (b) and (e) can only support the claim that $\mathrm{P}$ is positive if possession of $\mathrm{P}$ is possible. If possession of $\mathrm{P}$ is impossible, then it is better to lack $\mathrm{P}$ then to have $\mathrm{P}, \mathrm{P}$ detracts from excellence, and $P$ entails being limited. The claim that satisfaction of (a), (b), or (e) supports the claim that P is positive assumes that possession of $\mathrm{P}$ is possible. But Gödel's derivation is supposed to establish that possession of $\mathrm{P}$ is possible, and so cannot rely on the prior assumption that this is so.

$\mathrm{O}$ NTOLOGICAL ARGUMENTS HAVE always leant themselves to parodies. Consider the following frame for a higher-order ontological argument:

- For all first-order properties $\mathrm{P}$, if $\mathbf{P}(\mathrm{P})$ then $\sim \mathbf{P}(\sim \mathrm{P})$;

- For all non-empty sets of first-order properties $\Delta$, if, for all $\mathrm{P} \in \Delta, \mathbf{P}(\mathrm{P})$ and $\Delta$ entails $\mathrm{Q}$, then $\mathbf{P}(\mathrm{Q})$;

- $\mathbf{P}($ Necessarily existing);

- $\mathbf{P}(\mathrm{R})$; therefore

- There is a necessarily existing R-being.

There are various ways to interpret this frame:

1. $\mathbf{P}=$ positivity and $\mathrm{R}=$ God-likeness;

2. $\mathbf{P}=$ essential property of God and $\mathrm{R}=$ conjunction of essential properties of God;

3. $\mathbf{P}=$ originality and $\mathrm{R}=$ initial-singularity-ness; and

4. $\mathbf{P}=$ essential property of the initial singularity and $\mathrm{R}=$ conjunction of essential properties of the initial singularity.

(b) and (d) are arguments that their proponents will deem sound, but unsuited to convincing those on the other side. When it comes to soundness, (a) stands or falls with (b), and (c) stands or falls with (d). Originality picks out the properties of the initial singularity in just the same way that positivity picks out the properties of God. Does (a) or (c) offer an advantage for further argument? It is very hard to see how that could be the case.

Pruss argues that:

A reasonable way to read the Gödelian arguments is that they start with an intuitive notion of a positive property ... and attempt to formalise that property. The axioms are then attempts to codify our understanding of positivity. The notion of positivity maybe also comes along with, or perhaps flows from, a philosophical analysis of the concept of God as God $^{\dagger}$-likeness, as a being that has all strongly positive properties. ${ }^{15}$ 
Given that no account of positive properties can deem that impossible properties are positive, there is no non-question-begging way of choosing between the argument for God and the argument for the essentially Godless singularity, even given the further assumption that there is something that exists of necessity. It is not true that Gödelian ontological arguments start with an intuitive notion of a positive property: they start with a notion of a positive property that is intuitive to theists, and to theists alone. ${ }^{16}$

I N 1970, FOLLOWING a conversation with Gödel, Oskar Morgenstern wrote in his diary that, while Gödel was satisfied with the derivation, he would not publish it because he was afraid that people would conclude "that he actually believes in God, whereas is he is only engaged in a logical investigation (that is, showing that such a proof with classical assumptions (completeness, etc.) correspondingly axiomatized is possible." ${ }^{17}$ There is some evidence that Gödel was a theist, even at the time of the conversation with Morgenstern. ${ }^{18}$

Gödel was very interested in Leibniz's philosophy, and it is entirely credible that he sought only to show "that such a proof with classical assumptions (completeness, etc.) correspondingly axiomatized is possible." 19 While there is no evidence that Gödel would have accepted the claims I have made about the reasons for the failure of higher-order ontological arguments, there is no evidence that he would have rejected them either.

\section{Graham Oppy is Professor of Philosophy at Monash} University.

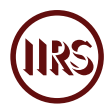

1. The main result was published in Kurt Gödel, "Die Vollständigkeit der Axiome des logischen Funktionenkalküls," Monatshefte für Mathematik und Physik 37 (1930): 349-60. It was republished, in an English translation, in Jean van Heijenoort, ed., From Frege to Gödel: A Source Book in Mathematical Logic, 1879-1931 (Cambridge: Harvard University Press, 1967), 582-91, under the title "The Completeness of the Axioms of the Functional Calculus of Logic."

2. These results were published in "Über formal unentscheidbare Sätze der Principia Mathematics und verwandter Systeme,I.," Monatshefte für Mathematik und Physik38 (1931): 173-98. It was republished, in an English translation, in Jean van Heijenoort, ed., From Frege to Gödel: A Source Book in Mathematical Logic, 1879-1931 (Cambridge: Harvard University Press, 1967), 596-616, under the title "On Formally Undecidable Propositions of Principia Mathematica and Related Systems."

3. His major work on this topic is Kurt Gödel, The Consistency of the Axiom of Choice and of the Generalized Continuum
Hypothesis with the Axioms of Set Theory (Princeton: Princeton University Press, 1940).

4. Kurt Gödel, "Rotating Universes in General Relativity Theory," Proceedings of the International Congress of Mathematicians in Cambridge 1 (1950): 175-81. Gödel's views on time are discussed in Palle Yourgrau, $A$ World without Time: The Forgotten Legacy of Gödel and Einstein (New York: Basic Books, 2004).

5. Anselm, Proslogion, 1078, Chapter II:

[Even a] fool, when he hears of ... a being than which nothing greater can be conceived ... understands what he hears, and what he understands is in his understanding.... And assuredly that, than which nothing greater can be conceived, cannot exist in the understanding alone. For suppose it exists in the understanding alone: then it can be conceived to exist in reality; which is greater.... Therefore, if that, than which nothing greater can be conceived, exists in the understanding alone, the very being, than which nothing greater can be conceived, is one, than which a greater can be conceived. But obviously this is impossible. Hence, there is no doubt that there exists a being, than which nothing greater can be conceived, and it exists both in the understanding and in reality.

6. Meditation V:

There is no less contradiction in conceiving a Godthat is to say, a supremely perfect being-who lacks existence-that is to say, who lacks some particular perfection-than in conceiving a mountain without a valley.

7. Historically important criticisms of ontological arguments include the claim, made by Gaunilo of Marmoutiers, that Anselm's argument could be adapted to produce an equally compelling proof of the existence of a perfect island, and Immanuel Kant's claim that ontological arguments all rely on the illicit assumption that existence is a real property of things.

8. See, for example, Christoph Benzmüller and Bruno Woltzenlogel-Paleo, "The Inconsistency in Gödel's Ontological Argument: A Success Story for AI in Metaphysics," in Proceedings of the 25th International Joint Conference on Artificial Intelligence, ed. Subbarao Kambhampati (Cambridge: AAAI Press, 2016), 936-42.

9. A detailed account of such a logic can be found in Randolph Goldman, "Gödel's Property Abstraction Operator and Possibilism," Australasian Journal of Logic 11 (2014): 1,448-52.

10. For a dissenting view, see Robert Koons, "Sobel on Gödel's Ontological Proof," Philosophia Christi 8 (2006): 235-47.

11. Any comprehensive discussion would also consider the derivations provided by Robert Maydole, "The Modal Perfection Argument for the Existence of a Supreme Being," Philo 6 (2003): 299-313; Maydole, R. (2012) "Ontological 
Arguments Redux" in Ontological Proofs Today, ed. Miroslaw Szatkowski (Heusenstamm, Germany: Ontos Verlag, 2012), 469-88.

12. See, for example, W. V. O. Quine, Philosophy of Logic (Cambridge, MA: Harvard University Press, 1970); and W. V. O. Quine, "Three Grades of Modal Involvement" in The Ways of Paradox and other Essays (Cambridge, MA: Harvard University Press, 1976), 158-77.

13. Obviously, we are not here aiming to enter into debate with those theists who deny that God has any properties. A certain species of friends of divine simplicity won't have any truck with higher-order ontological arguments. Conversation with them is for another time.

14. Alexander Pruss, "A Gödelian Ontological Argument Improved" Religious Studies 45 (2009): 347-53; Alexander Pruss, "A Gödelian Ontological Argument Improved Even More" in Ontological Proofs Today, ed. Miroslaw Szatkowski (Heusenstamm, Germany: Ontos Verlag, 2012), 203-14.

15. Alexander Pruss, (forthcoming) in The Ontological Argument, ed. Graham Oppy (Cambridge: Cambridge University Press).

16. It is perhaps worth noting here that it is not really clear that there is any very serious point to thinking about parodies of Gödelian ontological arguments. In the case of Anselm's Proslogion 2 argument, the reason why Gaunilo's parody is interesting is that it can be taken to show that there is something wrong with Anselm's argument without giving any clear indication of exactly where Anselm's argument goes wrong. At best, what Gaunilo's parody- or, perhaps, another relevantly similar parody-seems to show is that a full assessment of Anselm's Proslogion 2 argument requires development of a theory of objects that exist in the understanding, and, in particular, clear articulation of a comprehension principle that governs those objects. However, in the case of Gödelian ontological arguments, it seems pretty clear where these arguments fail, i.e., it seems pretty clear why these arguments fail to decide between, for example, theism and naturalism. There is nothing analogous to the development of a theory of objects that exist in the understanding that is required in order to get a grip on the failure of Gödelian ontological arguments.

17. Kurt Gödel, Collected Works III (New York: Oxford University Press, 1995), 388.

18. My best guess is that Morgenstern did not accurately record Gödel's fear. Given that it is likely that Gödel was a theist at the time of the conversation with Morgenstern, it is hard to see why he would have cared if people believed he was a theist. However, there is no reason to suppose that Gödel thought that his derivation was a successful proof of the existence of God. And it is perfectly reasonable to think that, if Gödel did not think his derivation was a successful proof of the existence of God, he would have feared people would mistakenly suppose that he did think his derivation was a successful proof of the existence of God.

19. Morgenstern, in a diary entry for August 29, 1970. See John Dawson, Logical Dilemmas: The Life and Work of Kurt Gödel (Wellesley, MA: AK Peters, Ltd, 1997), 307. 